\title{
THE EFFECT OF THE INTERNET ON THE PATIENT-DOCTOR RELATIONSHIP IN A HOSPITAL IN THE CITY OF SÃO PAULO
}

\author{
Jayr Figueiredo de Oliveira \\ EAESP-FGV - Fundação Getúlio Vargas, São Paulo, SP, Brasil
}

\begin{abstract}
Internet use by patients as a source of information on health and disease is expanding rapidly with obvious effects on the doctor-patient relationship. A self-administered questionnaire was used, about physicians' perception on the use of the Internet by patients and about whether that use interferes with the doctor-patient relationship. $85.3 \%$ of the physicians reported that their patients accessed the Internet and that $92 \%$ used that information in a following visit. Overall, $56.9 \%$ of the physicians thought that the Internet helped the doctor-patient relationship, $27.6 \%$ thought it interfered with the relationship, and $15.5 \%$ believed that the Internet had a negative impact on it.
\end{abstract}

Keywords: Internet, human relationship, health services, doctor-patient relationship, health information

\section{INTRODUCTION}

Widespread use of the Internet as a source of health information has had an effect on health knowledge, attitudes and practices of the general population as well as on the doctor-patient relationship. With hundreds of thousands of health-related websites and millions of health-related computer searches conducted each day (Eysenbach, 2003), the possibilities for rapid changes in health behaviors are enormous. The majority of health-related Internet searches by patients are for specific medical conditions. They are carried out before the clinical encounter, to seek information to manage their own health care independently, to decide whether they need professional help, or to overcome reticence in discussing personal issues. Searches are also carried out after the encounter for reassurance or because of dissatisfaction during the encounter (McMullan, 2006)

The fact that medicine has taken many turns in recent decades is not a novelty; the new reality is that patients have also changed. Medicine in former times, more of a craft than a science then, has today become technological. Patients, who in past times might have relied blindly on doctors, now attend an appointment having already provided themselves with information and vocabulary previously restricted to medical professionals - although, in some cases, they are only there to get a prescription from the doctor. Who is responsible for this transformation? We suggest it is the growing

Manuscript first received/Recebido em: 21/02/2013 Manuscript accepted/Aprovado em: 26/06/2014

Address for correspondence / Endereço para correspondência

Jayr Figueiredo de Oliveira, Bacharel e Mestre em Administração (PUC-SP), Doutor em Educação (PUC-SP), PósDoutor em Administração (EAESP-FVG). Pesquisador da EAESP-FGV - Fundação Getúlio Vargas, São Paulo, SP, Brasil, Av. 9 de Julho, 2029, Bela Vista, São Paulo - SP E-mail: profjayrfigueiredo@ gvmail.br 
influence of information and communication technology (ICT), and in particular the Internet, that is at the root of the change.

Access to websites with vast - but not always reliable - amounts of information on all sorts of diseases, as well as discussion forums, virtual communities, e-mail exchanges, and whatever else global search engines can offer, have contributed to revolutionizing the doctor-patient relationship. But are medical professionals prepared for this change? How to behave when patients believe they know everything about their illnesses? Should physicians participate in forum discussions and virtual communities or not? Should they send e-mails to patients or not? What attitude should a physician adopt toward a patient who fits this new profile?

Given the reality of this new patient behaviour profile, physicians and the most modern hospitals in the developed world have made many improvements in their use of ICT, with the latest hospital management processes fully computerized and technology applied in all phases of patient care (Valle, 2010). The implementation of electronic patient records is growing so dramatically that in a short period of time - about two to five years - it will allow all patients, in both the public and private hospitals of the city of São Paulo, to wear barcode wristbands, ensuring that physicians and nurses have immediate access to diagnosis and treatment information. In addition, hospitals are working towards specialized diagnosis and treatments for high complexity diseases and investing heavily in new technologies. In the future, always bearing in mind the role of personalized assistance and the supply of specific services, hospitals will be better prepared to serve patients in a holistic manner. The hospitals of the future should be better able to allocate human and technological resources to biological, psychological, and social care.

According to Hummel (2006), the intensive use of ICT will change the role of clinical staff (doctors, nurses, physiotherapists, and others) who will no longer perform mechanical tasks to take care of patients; instead, they will mainly offer emotional and psychological support. On the other hand, Hay, Cadigan, and Khanna (2009) claim that there remains an expectation of future hospitals having an increasing combination of technology and alternative therapies, and thus a path to prioritizing humanizing roles. Environmental and psychosocial activities and a fusion of Eastern with Western medicine will also contribute to a healing process towards quality of life improvement.

According to a survey by the World Health Organization (WHO), Brazil is the second largest producer of medical technology in emerging countries, second only to China. Brazilian industry sales in 2009 topped US\$2.6 billion in this sector, ahead of Mexico, India, and Turkey, which respectively held third, fourth, and fifth places in this ranking. The document released by the WHO in September, 2010, points to a greater participation of the emerging markets in medical technology. However, the medical equipment industry remains concentrated in developed countries. The United States tops the list with US\$91.3 billion sales in 2009, an amount equivalent to $40.7 \%$ of the market. Next, come Japan and Germany which account respectively for $10.1 \%$ and $8.1 \%$ of total sales in 2009 (WHO, 2010).

Between March 2003 and March 2010, Brazil invested more than US\$6 billion in infrastructure, research, and technology in the healthcare industry. These resources came from the Federal Government, the Brazilian Development Bank (BNDES), and research support agencies. Despite this progress, the country still has an approximate US $\$ 9$ billion trade deficit in the healthcare sector, according to 2009 data. Even so, the early investment results show a scenario allowing an optimistic view of the sector 
(WHO, 2010). According to the WHO, the medical technology market grows by about $6 \%$ per year. Total sales in 2008 amounted to US\$210 billion, double the amount recorded in 2001. The sector employs about one million people (WHO, 2010).

However, medical advances have not been recognizably associated with an increase in physicians' satisfaction with their career (Smith, 2001). As reported by Seckin (2010), patients are dissatisfied with their doctor-patient relationship. These stated factors, coupled with concerns on medical care expenditure increase and the emergence of conflicting issues between users and healthcare service providers have generated renewed interest in studies and reflections on the doctor-patient relationship.

In this context, particularly the changing dynamics of performance in the doctor-patient relationship, this article aims to identify and analyze the impact of Internet use, particularly on the human side of that relationship. The discussion is relevant to the presence of new technologies influencing the quality of care and debates about the role of the physician in the current working environment.

\section{LITERATURE REVIEW}

The widespread use of the Internet as a source of health information has caused a knowledge outcome towards attitudes and practices of people in general, as well as in the doctor-patient relationship. Thus, thousands of websites and millions of daily Internet health-related information searches (Kim \& Kim, 2009) enable an enormous and rapid change in health behaviour. Most Internet searches performed by patients before their clinic appointment are directed to specific clinical conditions. Information is sought with the objective of dealing independently with their own medical care, thereby being able to decide whether there is a need for professional help or not, and in some cases, overcoming reluctance to disclose personal matters. Searches may continue even after the appointment because of a lack of satisfaction with the most recent medical consultation or even to confirm the validity of what they have been told by their doctor." (Grossman et al., 2009).

Along with the benefits of easily accessible information, there are concerns about the quality of the obtained content and its effects on the doctor-patient relationship (Kim \& Kim, 2009). These concerns include unreliable information, which consequently may result in misguided self-treatment and wrong diagnosis; language barriers; commercial biases; longer clinic visits, resulting from disagreements on the patient's information presented to the health care professional; unnecessary tests and treatments resulting from the patient's Internet search (Walker \& Carayon, 2009). Thus, the physician's insight, experience, and encouragement are necessary to help the patient to accurately interpret and apply this information.

\section{Major approaches to the doctor-patient relationship}

The role of medicine in the second half of this century has been re-analyzed within several perspectives. In the late 1950s, the German physician and philosopher Karl Jaspers (1958/1991) developed a series of reflections on medical professionals in the age of technology with a strong criticism of psychoanalysis. He emphasized the need for medicine to recover the subjective elements of communication between doctor and patient that were improperly assumed by psychoanalysis and left aside by medicine, 
thus pursuing a path exclusively based on technical instrumentation and data objectivity.

Awareness of the need to develop a communicative interaction between doctor and patient started to expand in the 1960s through medical psychology studies (Coelho Filho, 2007) of doctors' psychoanalytic analysis (Montana et al., 2012), as well as the Balint groups' experience while introducing the psychological dimension of the doctorpatient relationship, and the psychotherapeutic training needed for physicians (Seckin, 2010). Among several other communication theories, must be noted the School of Palo Alto and some key members of the renowned "Invisible College": Gregory Bateson, Watzlawick, and Jackson (Watzlawick et al., 1972).

During the 1960s and through the 1970s, Talcott Parson's work dealing with the doctor-patient relationship and intentional consensus, which pioneered the field of health sociology and is now available as "informed consent," originated from exigencies of consumers' rights protection. A very current need to reduce the harmful effects from doctors' improper behaviour towards patients has resulted in an increase of complaints against them in various countries, parallel with the increase in health expenses. Thus, in the search for expenditure reduction, several studies have dealt with the quality of health services and guidelines for reorganizing the healthcare model, including users' points of view on service provision as presented by the healthcare system (Goodman, 2010). Most of these studies are based on the work of Donabedian, who in the early 1980s published several volumes and articles on this issue (Donabedian, 1990).

A survey by Boltanski (1979) dealt with doctor-patient communication in various regions of France. Boltanski discusses the differences between scientificmedical knowledge and family-medical knowledge and relates these differences to the doctor-patient relationship. This relation between professionals and the diseased is regarded as a source of anxiety, mainly by the lower classes, since they usually have no objective criterion of evaluation available to them, thus highlighting standard difficulties with communication and chiefly referring to the doctor as "not being honest." Boltanski's text, was used as a basis for many studies conducted in Brazil.

Another perspective presented by Russ et al. (2011) analyzes the doctor-patient relationship from an anthropological point of view, not only the cultural component of the disease, but also the experience and point of view of patients and relatives, interpretations, popular practices, and their resulting influence on prevention, diagnosis, and treatment. These authors' research has had a large influence on the course on doctor-patient communication offered at Harvard Medical School (Branch et al., 1991), as well as other training programs (Seppilli \& Caprara, 1997), resulting in a key component in undergraduate training and postgraduate studies in the medical field (Usherwood, 1993).

Contemporaneously, the doctor-patient relationship has been targeted as a key aspect of improving healthcare quality and divided into several components such as personalized care, humanization of care, and right to information (Goodman, 2010), dealt with through topics such as users' degree of satisfaction with healthcare services (Taha et al., 2009), counseling (Godfrey \& Johnson, 2008), physician-patient communication (Kivits, 2009), patient suffering, biomedicine's purpose (Giveon et al., 2009), and informed consent (Goodman, 2010).

Among Brazilian authors, such as Salles (2010), Sucupira (1982), Coelho Filho (2007), it is possible to observe that arguments related to this issue are discussed again; 
however, these have been in the form of essays presenting opinions or declaring theoretical inspirations. Two works stand out as being based on a systematic analysis to a large extent. Sucupira's (1982) study would be the first of this kind to be developed. At the time the study was conducted, the Brazilian population was served primarily by three systems operating in parallel: social security, medical groups, and state and municipal health centers. Sucupira's analysis, focusing on childcare assistance, indicates consumers' choice patterns, resulting from the evaluation of a problem which triggered a search for service, in the context of the care system characteristics at the time. This research, in the view of the consumer, took into consideration physical conditions, accessibility, efficiency, professional availability, and medicines. For example, it was considered that the best childcare could only be found at the National Institute of Health and Social Security (INAMPS), and not at the State Medical Center. The main reason was that at the INAMPS it was always possible to visit the same doctor. This was evidence that these three big providers had different models for health care, which were recognized by the public, thus providing an option for them to choose the most suitable model to their needs in their search for care services, including relational dimension aspects.

In his new environmental analysis, Goodman's (2010) study is particularly relevant. He interviewed doctors with extensive clinical practice to examine the way they included technology in their professional activities. This analysis, from a pronounced historical-structure perspective, demonstrates that doctors, unlike other professionals, have not lost the property of "knowing" and "applying" when faced with the capitalist model of consolidation. However, parallel to this social transformation, we can observe the valuing of science and the intellectualization of knowledge. Medicine would have gone through the universalization of its actions, having patients as the object of their cognition, and in such circumstances, social differences would be left aside, giving priority to the object of scientific wisdom. In such conditions, the medical process is configured as a repetitive act of knowledge enabled by science, having thus entered the world of serial production, a factor which marks the industrial technology society (Goodman, 2010).

\section{Confidence in the doctor-patient relationship}

The focus of power in health care is shifting: instead of the doctor acting as sole manager of patient care, a consumerist model has emerged in which patients and their doctors are partners in managing their care. A number of studies focus on whether the Internet can actually empower patients and enrich the patient-doctor relationship (Shoor and Lorig, 2002; Sinclair, 2007).

Trust has been described as one of the scarcest medical products (Attfield et al., 2006). The era of "the doctor knows best" lasted for most of the twentieth century because of the lack of information. However, with the arrival of the information age, patients came under the influence of the digital revolution. The immediate reaction has been that confidence in the doctor is replaced by skepticism and discouragement. "Blind trust" is replaced by "informed trust." In fact, the first medical contact, which traditionally was with the family doctor, is being slowly replaced in many cases by the Internet. Patients search on medical websites and then consult their doctors armed with that information. A study of 500 "health seekers" revealed that $55 \%$ of them obtained information online before visiting the doctor and that $32 \%$ sought information about a particular doctor or hospital (Fox \& Rainie, 2002). Among those who considered their 
search of websites a success, 38\% reported that it led them to ask their doctor new questions or even opt for a second opinion (Fox \& Rainie, 2002). "Virtual patients" across Europe also seem to be following this trend; a recent Internet study of a website in five languages found that among 6.699 European respondents, 73\% indicated doctors as their favourite source of health information, although $45 \%$ also used the Internet, while $19 \%$ mentioned the Internet and not the doctor as a favourite source (Health and Age, 2011). According to the Research Center for Information and Communication Technology, among 63 million people in 2009 using Internet access in Brazil, 39\% were people living in large urban centers looking for health information, representing a growth of $6 \%$ per annum among people interested in this type of query.

Grosseman and Stoll (2008), however, warn that a large resistance from healthcare professionals has been noticed against the modification of the doctor-patient relationship dynamics in the age of information, owing to a bigger concern on the inconsistent and seldom reliable medical information on the Internet, the waste of the human factor, and the problematic perception of the informed patient.

\section{Contribution of ICT in the Medical Field}

In a complex universe formed by multiple and diversified organizations, ICTs have become competitively instrumental in driving and positioning virtually any organization, often transforming the reality and essence of the business itself. Given the enormous potential, organizations are leading the development and application of ICTs, either through the optimization of internal works or by inducing changes at the business level, thereby capitalizing on ICT developments in order for them to become more dynamic and better qualified to innovation in response to market changes (Hummel, 2006). Propelled at first through successive technological advances, in terms of equipment and software, then through an increasing recognition of its potential, ICTs have emerged from the gloomy condition of doing mainly automation tasks in organizations, in order to make an up-to-date assessment (Hummel, 2008) as a determining factor for competitive positioning.

ICTs are the bedrock of contemporary organization. Currently, it is almost impossible to conceptualize an organization that does not use ICT; it would not be excessive to say that the effects of ICT have been (and certainly will continue to be) fully integrated in organizations (Valle, 2010), whether from the point of view of incorporating these technologies into the value chain of the enterprise or from the point of view of establishing a competitive advantage.

As an important catalyst for change in the manner that work is performed, information technologies also play a key role in the health sector (Hummel, 2008). As a whole, the advent of the Internet has led this industry to exploit ICTs in order to improve patient care in hospitals, increase the commercial effectiveness of institutions, and optimize communication between the various players in the sector (MacGregor et al., 2010).

As MacGregor et al. (2010) state, several studies identify the potential benefits of ICT use in the health sector. For instance, Akersson et al. (2007) refer to service quality improvement and information availability. El-Sayed and Westrup (2003) suggest that ICT use in hospital practices improves communication, causing business effectiveness growth and contributing to new enterprise initiatives. 
Seckin (2010) suggests that ICT supports and allows complex interactions between, for example, doctors, nurses, patients, and sometimes facilities. Hummel (2008) suggests that when ICT is applied to medical practices, it produces a change in procedures which result in a more effective final product. Goodman (2010) reports an increase in the financial income. Ray and Mukherjee (2007) note the use of ICT in management and planning development. Other studies such as the ones by Lougheed (2004) and Ho et al. (2004) show that the current use of ICT transcends the context of clinical tools, incorporating a wider role for management practice tools in business.

It becomes clear that, without an efficient and effective use of ICT, organizations cannot be efficient or competitive, and in most cases, they depend on these abilities to survive (Hummel, 2006). Given the importance of the Internet today in the context of organizational development, it is essential to characterize the current reality in terms of its adoption in hospitals, in the interest of improving evaluation and future planning.

\section{Technological Investment in the Health Sector}

An increasing worldwide emphasis in the health sector has been observed in recent years, mainly among Western countries and the United States, where a growth of per capita expenditures on health has been witnessed (OECD, 2008). This change is related to many aspects of the contemporary society, including increase in life expectancy, and demand from people for a better quality of life and better health services. At the same time, we are witnessing efficient approaches in terms of costs and new solutions based on ICT.

In many Western countries, the health industry sector is large (Salles, 2010). Expenditures in the United States were US\$2.2 trillion in 2007, accounting for $16 \%$ of GDP, with an expected growth rate of $6.2 \%$ per year through 2018, reaching US $\$ 4.4$ trillion, corresponding to 20\% of GDP in 2018 (Medicare.gov, 2007). Meanwhile, in Europe (EU-25) in 2006, total health expenditures rose to $7.76 \%$ of GDP; the EU-15 the average was 8.6\% and in the new Member States 5.8\% (OECD, 2008).

However, many factors are contributing to this increase in expenditure on health matters. The main factor is a combined effect of a predictable increase in the aging population along with a tendency for per capita expenditures on health to increase with age (Hummel, 2008). However, life expectancy increase and health care charges do not have a linear relationship as people not only require longer periods of treatment, but also frequency and intensity of health care increases.

According to Salles (2010), the intention to computerize and mechanize medicine was commendable: it was thought that this would grant the doctor better conditions to be faster and more efficient, thus allowing an increase in time spent on the patient and on other work. It would also permit faster and more accurate laboratory tests - especially those applying higher technology such as MRIs, CT scans, and genetic research, among other advances strictly connected to medical practice. However, an element that should have been helping medical practice instead began to control it; the medical activity of value became the technology-aided information search, while doctors started to become an obsolete article rather than a profit generator.

Pressured by the healthcare administrations of hospitals, clinics, and even healthcare systems, doctors are nowadays required to see a predetermined number of patients per month, and if they do not reach this quota, they are considered incompetent 
and unproductive (Salles, 2010). The physician must work in a scheme that does not provide the necessary time for listening to, or developing a rapport with, the patient and then the patient's trust - a necessary condition for a query to be considered satisfactory in any area of healthcare assistance. In the few predetermined minutes of a healthcare query, the physician hardly has time to look at the patient's name and discover the patient's needs through a conversation; instead, the physician has to proceed with standard questions that in turn merely standardize the patient. This process dismisses the clinical examination and arrives at a diagnosis primarily through laboratory tests (Salles, 2010).

Moreover, science and technology have lately been providing healthcare professionals with a wide range of "tools." Advances in pharmacology, material science, nanotechnology, ICT, and medical practice, contribute to new or improved healthcare mechanisms. Orientation towards innovation and competitiveness among enterprises has also pushed the development of many new medical devices and solutions (European Commission, 2007). The Brazilian market has grown in the area of health technology (public and private); the merging of Brazilian companies with foreign companies to attain the right to technological patents has alone generated billions of dollars. However, Brazilian laws do not allow foreign investment in healthcare (Valle, 2010; Hummel, 2008)

\section{The Doctor-Patient Relationship and Information Access in the Internet Age}

Scientific and technical information access generally, coupled with the increase in the educational level of the population, has created a class of patients who seek information on illness, symptoms, medications, and costs of hospitalization and treatment. There has also been an increase in information availability and access in the field of health care, substantially through the Internet (Pereira Neto \& Guilam, 2008). The main feature that differentiates the Internet from other media is the plethora of information sources and the dynamic stance of the user. This information obtained through the Internet modifies or interferes with the doctor-patient relationship (Pereira Neto \& Guilam, 2008).

Doctors are no longer the sole holders of supreme knowledge; rather, they are now being questioned by increasingly well-informed patients (Kim \& Kim, 2009). People can now use the Internet to look up information on their complaints or on diseases they already know they have, and they can do this before going to their medical consultation. Usually the main point of entry is the Google search engine (Siempos et al., 2008). From there, they dive into specialized websites and blogs (Russ et al., 2003; Tang \& Ng, 2006). It is estimated that half of the patients coming to the doctor's office now bring information from the Internet. The doctor then has to realize that the patient has this information, and then patients should realize that the doctor has the information and the training and ability to apply that information (Pereira Neto \& Guilam, 2008).

\section{RESEARCH METHODOLOGY}

A descriptive exploratory study was conducted with a cross-sectional quantitative approach. The investigated population was composed of doctors performing professional activities in a large hospital in the central part of the city of São Paulo, Brazil - carried out between the second half of 2011 and first half of 2012. 
The survey population included physicians practicing in various specialties (obstetrics and gynecology, pediatrics, cardiology, and pulmonology, among others) caring for patients in their own offices or directly on the premises of the hospital. They agreed to be participants in the study through a consent form.

Data were collected for three months through a self-administered questionnaire developed by the author, composed of open and closed questions on physicians' perceptions on Internet use by patients and on whether this interferes with the doctorpatient relationship. The interviewees were anonymous, and identification data were treated as confidential by separating questionnaires from the consent forms in two different sealed envelopes.

Data were entered into the EpiData program and analyzed with the SPSS version 19. Qualitative data were presented in absolute and relative values and quantitative data as measures of central tendency and dispersion. In order to test associations between the variables of interest, a chi-square test was used for categorical variables, and the oneway ANOVA to compare means, tested at the statistical significance level of $95 \%$.

The open-ended questions were transcribed and grouped as quotations, in order to illustrate the medical opinion of professionals on the subject in question.

\section{RESULTS}

The study included 232 physicians, at an average age of 43.6 (SD \pm 11.3 ), ranging between 30 and 60 years. A total of $75.9 \%$ were male. Regarding the medical practice period, the average was $18.6 \pm 10.6$ years, ranging between 5 and 35 years on the job. Table 1 shows the participants' specialties. Besides their medical specialization, $29.3 \%$ among them had a master's degree and $6.9 \%$ a doctorate's degree.

\begin{tabular}{lcc}
\hline \multicolumn{2}{c}{ Table 1 - Specialty of Medical Professionals Participating in the Study } \\
\hline \multicolumn{1}{c}{ Medical specialty } & $\mathrm{N}$ & $\%$ \\
\hline Pediatrics & 40 & 17.2 \\
Gynecology and obstetrics & 34 & 14.7 \\
Gastroenterology & 28 & 12.0 \\
Clinical medicine & 14 & 6.0 \\
Cardiology & 12 & 5.2 \\
Endocrinology & 12 & 5.2 \\
Other * & 92 & 39.7 \\
\hline
\end{tabular}

* Other medical specialties: nephrology, neurology, angiology and vascular surgery, ophthalmology, dermatology, pulmonology, geriatrics, hematology, infectious diseases, family medicine, oncology, orthopedics, proctology, psychiatry, acupuncture, rheumatology, urology.

Among the participating physicians, 96.6\% usually accessed the Internet and 99.1\% had an e-mail account. Overall, $85.3 \%$ of respondents thought that patients accessed the Internet to search for information on their medical condition or for information on the symptoms that caused them to seek medical attention. But within their own clientele, they estimated that less than $50 \%$ of the patients they treated had this attitude, according to the medical professionals interviewed. 
When questioned as to whether patients accessed the Internet themselves after a doctor's appointment, $95.7 \%$ of the physicians believed their patients access the Internet after treatment. However, physicians pointed out that in their opinion around $92 \%$ of patients use information obtained from the Internet to talk to their doctors at the next appointment.

On the socioeconomic profile of patients, doctors believed that only $2.6 \%$ of patients from the Unified Health System (SUS) used the Internet. The vast majority $(65 \%)$ were private or health plan patients, leading to the conclusion of a more widespread use of Internet searches among individuals with higher purchasing power.

For $46.6 \%$ of respondents, the opinion was that patients who attended the doctor's office after reading a lot of information on the Internet usually made their appointments last longer. However, a considerable number of physicians $(31.9 \%)$ did not perceive this difference of time. Furthermore, $42.2 \%$ of the doctors stated that they had patients arriving with information from the Internet, which was new to even the professionals themselves. The Internet was also used as a tool for updating their professional knowledge by $94 \%$ of the interviewed physicians and $58.6 \%$ of them stated they liked to suggest trustable sites to their patients.

When patients came to the clinic with a large amount of Internet-obtained information regarding their illnesses, doctors had different emotional reactions. Of the total, $50 \%$ felt motivated or happy, $25 \%$ felt indifferent, $14 \%$ had confused feelings, and $11 \%$ felt uncomfortable.

Comparing average age to period of practice, younger and less experienced physicians had a higher percentage of negative feelings towards patients getting medical information on the Internet. However, this difference was not statistically significant ( $p>0.05)$. Also, differences between gender in feelings were not detected $(p=0.6)$, nor by medical field $(\mathrm{p}=0.3)$ or postgraduate status $(\mathrm{p}=0.9)$.

In the doctors' opinion, $56.9 \%$ believed the Internet helped the doctor-patient relationship, $27.6 \%$ thought it interfered with it and $15.5 \%$ believed that the Internet had a negative impact on it. Among the professional opinions of those who believed that the Internet helped the doctor-patient relationship, highlight those who believe that it can improve the communication between practitioners and patients, helping to treat the disease.

Presented below are illustrations of opinions from selected interviews with the doctors. To preserve confidentiality, the physicians are identified only by number, from M1 to M13 - and elected only to exemplify some of the opinions collected:

M1: "It helps them to understand a little more about their disease; it also becomes easier to explain the treatment and its consequences."

M2: "The higher the level of information and knowledge the patient has about their disease, the better is their acceptance of the treatment. Patient participation is extremely important for making decisions; it is also necessary to share guidelines, so that the desired effect may result from the treatment."

M3: "It helps, since it solves doubts that sometimes are not reachable in a conversation."

In addition, some professionals considered the Internet an optimizing tool for acceptance and understanding of diseases, with patients thus becoming more favourable to medical care: 
M4: "In cases of chronic diseases, it is an important tool; experience shared among patients makes them aware of the dimensions of their own disease."

M5: "... can be used as an auxiliary tool during consultation."

M6: "It is far better to have a discussion with a patient, when they are aware of their illness, aiming for the best approach through mutual sharing of responsibilities and decision making."

Among those doctors who believed that Internet information use by patients undermined the doctor-patient relationship, there were concerns over somatization symptoms or psychological interference resulting from misinformation or poor understanding:

M7: “... patients may sometimes access sites with poor quality information or even interpret this data improperly, thus creating anxiety before the exact diagnosis."

M8: "In cases where a patient believes most of what they read on the Internet, this can induce them to feel the symptoms that they have read about, even if they don't in fact exist."

M9: "Internet can be harmful, when patients create an expectation that can sometimes be disappointing when faced with the knowledge of an actual disease stage or erroneous information obtained through unreliable websites."

M10: "The large amount of fallible information on the Internet causes a negative effect on the acceptance of a disease by the patient."

There are some professionals who feared they were being "tested" on information they are unaware of:

M11: "In some cases, a distrustful patient misuses the information obtained by trying to test the physician's knowledge."

A considerable number of physicians $(27.6 \%)$ believed that Internet use by patients, as a complementary method, did not involve either damage or benefit, i.e., this newly adopted attitude of many patients did not interfere with the doctor-patient relationship:

M12: "Knowledge must be multiplied, democratized. The patient has the right to seek information on his disease wherever they want. There is good quality information to be found, as well as bad, but that should not interfere with the doctor-patient relationship."

M13: "Patient knowledge improvement and communication is made easier; therefore, there is no reason to believe that it may interfere with the doctor-patient relationship."

Doctor's age and length of time in practice had no significant statistical association with either positive or negative opinions of the Internet on the doctorpatient relationship ( $\mathrm{p}=0.4$ and $\mathrm{p}=0.5$, respectively), similarly for post-graduate qualification $(\mathrm{p}=0.3)$. However, when comparing specialties, grouped by clinical and surgical categories, clinicians had a more favourable opinion of the Internet than surgeons, and this difference was statistically significant $(\mathrm{p}=0.03)$. 
Table 2 - Quality of Health Information on the Internet as Perceived by Doctors

\begin{tabular}{l|c}
\hline Opinion of health information on the Internet & $\mathrm{N}(\%)$ \\
\hline $\begin{array}{l}\text { Important to understand the disease and adherence to } \\
\text { treatment }\end{array}$ & $136(58.6)$ \\
Unnecessary, since most information is incorrect & $30(12.9)$ \\
$\begin{array}{l}\text { It makes no difference; the patient should follow medical } \\
\text { guidelines }\end{array}$ & $16(6.9)$ \\
Depends on the source investigated & $50(21.6)$ \\
\hline
\end{tabular}

Table 2 summarizes doctors' opinions on information available on the Internet.

\section{DISCUSSION}

Among the 232 physicians surveyed in this study, $85.3 \%$ answered that it was common for patients to access Internet information about their medical condition or about whatever other matter made them seek medical attention. This result is very similar to that of other studies, such as a Norwegian survey that discovered the proportion of the population seeking Internet information related to health increased from $31 \%$ in 2001 to $58 \%$ in 2005 (Andreassen et al., 2006).

Estimates from other studies show that half of patients come to clinics with Internet information (Pereira Neto \& Guilam, 2008). For example, a US study estimated that 70 million Americans used the Internet to obtain health-related information (Seckin, 2010). A Spanish study stated that around 40\% of their population surfed the Internet for health information (Sobes, 2009); however, in this study it was estimated, according to medical professionals, that less than $50 \%$ of their patients did so during their treatment. It is likely that this difference between surveys occurred because of methodological differences in the studies. Also, the present study is a private estimate given by medical personnel and does not necessarily reflect what happens in practice, since patients may in fact access the Internet but do not mention it to their doctors.

Comparing average age and period of practice, this study indicates that younger and therefore less experienced professionals had a higher percentage of negative feelings towards patients' habit of searching medical information on the Internet. This opinion might be associated with the uncertainty of newly graduated doctors, due to their limited experience in professional practice. These professionals may fear being tested or not being aware of some information, as expressed by M11: "In some cases, a distrustful patient misuses the information obtained by trying to test the physician's knowledge."

Comparing specialties grouped as clinical or surgical, clinicians had a more favourable opinion about the Internet than surgeons, and this difference was statistically significant $(\mathrm{p}=0.034)$. Perhaps, this is justified because clinicians generally maintain a longer period of contact with patients, especially when treating chronic diseases; they also understand better how health information works to assist treatment adherence and lifestyle improvement. 
This study showed how common it is for patients to access the Internet after a medical consultation. Observations pointed to about $92 \%$ of patients using information obtained through the Internet, to use for discussion at their next doctor consultation. In another study with 3.209 participants, $31 \%$ had reported information seeking related to health, and only $8 \%$ among these used this Internet data to share with their doctor (Hay, 2009). There is a possible explanation for this new patient profile, and this is the guarantee of anonymity on the Internet. One of the positive aspects of this new change is that the patient is free to search about intimate aspects, thanks to the anonymity of the network, thus providing greater adherence to proposed treatments, and as a result, patients become more involved in medical consultations (Melamud et al., 2007). For this same reason, in the present study over half the physicians surveyed $(58.6 \%)$ believed that the information found on the Internet was important for the patient to acquire medical knowledge on the disease, achieving adherence to treatment, and that this is a reason for improvement in the development of the doctor-patient relationship. Given the informal and accessible language used on the Internet, patients could achieve better understanding and be enabled to more effectively discuss treatment options with their doctor, thus also sharing the responsibility of decision making (Madeira, 2006; Gauld \& Willians, 2009).

When patients attend the doctor's office after reading a lot of information from the Internet, the appointment lasts longer, as opined by $46.6 \%$ of the physicians surveyed. This probably occurs because patients who are in possession of a greater amount of knowledge on their disease have more curiosity and extra questions regarding the approach to be adopted by their doctors. However, a considerable number of physicians $(31.9 \%)$ do not perceive this difference in consultation time, as justified by one of the doctors interviewed (M1): "It helps them to understand a little more about their disease; it also becomes easier to explain the treatment and its consequences." Moreover, this new patient profile requires doctors to be constantly updating their professional knowledge (Pereira Neto \& Guilam, 2008). It seems that it is not only patients who are turning to the Internet, since $94 \%$ of physicians in the present study used it to update themselves, 96.6\% had Internet access, and 99.1\% used email. As a result, 58.6\% of physicians were suggesting reliable sites to their patients for responsible use. This approach to technology by some physicians may result from the aim to offer accurate and easily interpreted information access. Perhaps, there is also some fear among professionals that they may not be aware of latest information and they must face the fact that their career practice requires continued improvement. In one study conducted in Mexico, some cases were reported where patients had modified their behaviour after presenting medical information obtained on the Internet to their doctors (Herrera, 2008).

In the present study, $42.2 \%$ of the doctors said that they were unaware of some of the Internet information presented by patients. This could be explained by the fact that some of this information was incomplete, contradictory, inaccurate, or even fraudulent. A Brazilian study in São Paulo assessed the impact of Internet use on the doctor-patient relationship, observing the danger of people thinking that information obtained on the Internet can be used to treat themselves without even consulting a doctor, as this would be unwise (Hummel, 2008).

It is important to evaluate how patients use this Internet information, bearing in mind that patients may encounter difficulties understanding medical language as well as doubts arising from the multiplicity of information. It is indeed hard for a patient to distinguish right from wrong or even traditional procedures from novelties (Herrera et 
al., 2008). The consideration remains, therefore, whether patients are able to interpret in a proper manner the information they obtain. Among these negative aspects is a remarkable naivety in believing uncritically all available information from the Internet. That is why, despite the importance associated to the liberal and democratizing facets of the Internet, it is necessary to possess the technical and cultural prerequisites to access it intelligently. For example, we have (through physicians' perception) a socioeconomic profile of patients who use the Internet: they are high-income individuals, represented by private healthcare or health insurance.

Most patients find health information on the Internet to be as reliable as that from other sources, including information provided by physicians (Pereira Neto \& Guilam, 2008; Marsiglia, 2006). Anyone surfing the net is liable to encounter criminal (counterfeit or prohibited drugs being sold, promises of miracle cures) or at least unethical activities (informative contents with the sole intention of selling drugs or medical procedures).

It is also possible to find nonsensical information that may generate severe damage to health. Thus emerges the quality control problem of Internet content that is related to health (MacGregor et al., 2010). Of the 232 doctors interviewed, $15.5 \%$ believed that the Internet disrupted the doctor-patient relationship, and $12.9 \%$ considered the Internet information available to be unnecessary since much of it was incorrect.

Among the limitations of this study is a lack of scientific literature on the topic. The focus of this research has therefore rested on the point of view of physicians regarding the new attitude adopted by patients. It is therefore of consequent importance to emphasize that the research is based on estimates taken from the personal impressions of doctors, and it does not necessarily reflect what happens in practice. Further studies may be needed to evaluate more precisely this new patient profile and its repercussions on the doctor-patient relationship.

\section{CONCLUSION}

The role of information in determining a diagnosis or treatment is of fundamental importance to both doctor and patient, though with different influence factors for each. For medical professionals, there is the important role of training and updating of knowledge in their field; while for patients, the search for information may be a messy process that can exert either a positive or negative influence on the established doctor-patient relationship.

In this study, the opinion of medical professionals was directed to the question of how the Internet affected the doctor-patient relationship. In the doctors' opinion, $56.9 \%$ believed the Internet helped the relationship, $27.6 \%$ thought it interfered with it, and $15.5 \%$ believed that the Internet had a negative impact on it.

As a conclusion, we observe that the theoretical frame of this question as an object of study still requires a significant amount of further research and published findings that tie together and comprehensively articulate the theory and empirical analyses and evaluations of proposed interventions. Regarding the doctor-patient relationship, there may need to be some rethinking of it, which places the patient in a position which is as active as the physician's, to the extent that the patient's complaint 
guides the clinical moment. This rethinking of the place of the patient is essentially one of the targets of any project on the humanization of medicine.

This research, however, should be a priority for a context supported by practical learning through reflection, without denying or belittling the technological resources in the daily lives of the profession, but using them as a resource and not a purpose of health interventions.

\section{REFERENCES}

Akersson, K.; Saveman, B. I.; Nilssom, G. (2007). Healthcare consumers' experiences of information communication technology: A summary of literature. International Journal of Medical Informatics, 76(9), 633-645.

Andreassen, H. K.; Trondsen, M.; Kummervold, P. E.; Gammon, D.; HJORTDAHL, P. (2006). Patients who use e-mediated communication with their doctor: new constructions of trust in the patient-doctor relationship. Qual Health Res, 16(2), 238248.

Attfield, S.; Adams, A.; Blandford, A. (2006). Patient information needs: pre and post consultation. Health Informatics Journal 12, 165-177.

Boltanski, L. (1979). As Classes Sociais e o Corpo. Rio de Janeiro: Edições Graal.

Branch, W. T.; Arky, R. A.; Woo, B.; Stoeckle, J. D.; Levy, D. B.; Taylor, W. C. (1991). Teaching medicine as a human experience: A patient-doctor relationship course for faculty and first-year medical students. Annals of Internal Medicine, 114, 482-489.

Coelho Filho, J. M. (2007). Relação médico-paciente: a essência perdida. Interface Comunicação, Saúde, Educação, 11(23), septiembre-diciembre, 631-633. Retrieved July 7 2010, from http://redalyc.uaemex.mx/src/inicio/ ArtPdfRed.jsp?iCve $=180115440018$.

Donabedian, A. (2007). La Qualita dell'Assistenza Sanitaria. Roma: NI.

El Sayed, H.; Westrup, C. (2003). Egypt and ICTs: How ICTs bring national initiatives, global organizations and local companies together. Information Technology \& People 16(1), 76-92.

European Commission. (2007). eHealth - Priorities and Strategies in European Countries. Luxembourg: Office for Official Publications of the European Communities.

Eysenbach, G. (2003). The impact of the 1. internet on cancer outcomes. CA Cancer J Clin, 53(6): 356-371.

Fox, S.; Rainie, L. (2002). Pew Internet and American Life Project. "Vital Decisions", Summary of Findings, and Part Six: Impact, Washington, DC, May. Retrieved April, 17, 2012 from http://www.pewinternet.org/pdfs/PIP_Vital_Decisions_May2002.pdf.

Gauld, R.; Willians, S. (2009). Use of the Internet for health information: a study of Australians and New Zealanders. Inform Health Soc Care, 34(3), 149-158.

Giveon, S.; Yaphe, J.; Igal Hekselman, I.; Mahamid, S.; Hermoni, D. (2009, September). The e-Patient: a survey of Israeli primary care physicians' responses to patients' use of online information during the consultation. IMAJ 11. 
Godfrey, M.; Johnson, O. (2008). Digital circles of support: meeting the information needs of older adults. Comput Hum Behav, 25, 633-642.

Goodman, K. W. (2010). Ethics, information technology, and public health: new challenges for the clinician-patient relationship. In: Symposium - the effects of health information technology on the physician-patient relationship. Journal of Law, Medicine \& Ethics. Spring.

Grosseman, S.; Stoll, C. (2008). O ensino-aprendizagem da relação médico-paciente: estudo de caso com estudantes do último semestre do curso de medicina. Revista Brasileira de Educação Médica, 32(3), 301-308.

Grossman, J. M.; Zayas-Cabán, T.; Kemper, N. (2009, March/April). Information gap: can health insurer personal health records meet patients' and physicians'needs? Health Affairs 28(2), 377-389.

Hummel, G. S. (2006). eHelth: o iluminismo digital chega a saúde. São Paulo: STS. Paulo: STS.

G. S. (2008). ePatient: A odisseia digital do paciente em busca da saúde. São

Hay, M. C.; Cadigan, R. J.; Khanna, D. et. al. (2009). Prepared patients: Internet information seeking by new rheumatology patients. Arthritis Rheum, 59(4), 575-82.

Health and Age, (2011). "Europeans require more health information: Survey results from Europe." Retrieved February 8, 2012, from www.healthandage.com.

Herrera, C.; Campero, L.; Caballero, M.; Kendall, T. (2008). Relationship between physicians and HIV patients: influence on adherence and quality of life. Rev Saude Publica, 42(2), 249-255.

Ho, K.; Lauscher, H. N.; Best, A.; Walsh, G.; Jarvis-Selinger, S.; Fedeles, M.; Chockalingam, A. (2004). Dissecting technology-enabled knowledge transition: essential challenges, unprecedented opportunities. Clinical and Investigative Medicice, 27(2), 70-78.

Jaspers, K. (1958/1991). Il Medico nell'Età della Tecnica. Milano: Raffaello Cortina Editore. [ed.orig.: Der Arzt im technischen Zeitalter, Klinische Wochenschrift, 36 (1958), 1037-1143.]

Kim, J.; Kim, S. (2009). Physicians' perception of the effects of Internet health information on the doctor-patient relationship. Inform Health Soc Care, 34(3), 136-48.

Kivits, J. (2009). Everyday health and the Internet: A mediated health perspective on health information seeking. Sociol Health Illn. 31(3), 673-687.

Lougheed, T. (2004). Wireless points the way in Africa. Appropriate Technology, 31(3), 50 .

Macgregor, R. C.; Hyland, P. N.; Harvie, C. (2010). Associations between driving forces to adopt ICT and benefits derived from that adoption in medical practices in Australia. In: Handbook of research on developments in e-health and telemedicine: technological and social perspectives. IGI Global.

Madeira, W. (2006). Navegar é Preciso: avaliação de impactos do uso da Internet na relação médico-paciente. [Dissertação de Mestrado]. Faculdade de Saúde Pública da USP. São Paulo: 132p. 
Marsiglia, I. (2006). Impacto de la tecnologia médica sobre la historia clínica y la relación médico-paciente. Gac Méd Caracas, 114(3), 183-189.

Mcmullan, M. (2006). Patients using the Internet to obtain health information: how this affects the patient-health professional relationship. Patient Educ Couns, 63(1-2), 24-28.

Medicare.GOV. (2007). National Health Expenditure 2008-2018, Forecast summary. $\begin{array}{llll}\text { Retrieved April 8, from } & 2012 \text { 8 }\end{array}$ http://www.cms.hhs.gov/NationalHealthExpendData/downloads/proj2008.pdf.

Melamud, A.; Puiggari, J.; Goldfarb, G.; Cairoli, H.; Otero, P. (2007). Información sobre salud em internet: su empleo por pediatras y padres de pacientes. Arch Argent Pediatria, 105(6), 513-516.

Montana, S. B.; Montana, G. L.; Moshavi, D. (2012). A knowledge-based view of improving the physician-patient relationship . Academy of Health Care Management Journal, 8(1), 9-19.

OECD, OECD Health Data 2008. Retrieved April 13, 2012, from http://ec.europa.eu/health/ph_information/dissemination/echi/echi_25_en.pdf.

Pereira Neto, A. F.; Guilam M. C. R. (2008). The Internet, expert patients and medical practice: An analysis of the literature. Interface comun. saúde educ., 12(26), 579-588.

RAY, S.; Mukherjee, A. (2007). Development of a framework towards successful implementation of E-governance initiatives in health sector in India. International Journal of Health Care, 20(6), 464-483.

Russ, H.; Giveon, S. M.; Catarivas, M. G.; Yaphe, J. (2011, April). The effect of the internet on the patient-doctor relationship from the patient's perspective: a survey from primary care. IMAJ, 13.

Salles, A. A. (2010). Transformações na relação médico-paciente na era da informatização. Revista Bioética, 18(1), 49-60.

Seckin, G. (2010). Patients as information managers: the Internet for successful selfhealth care \& illness management. Open Longevity Science, 4, 36-42.

Seppilli, T.; Caprara, A. (1997). Il Rapporto Medico-Paziente: Un Approccio Antropologico, Corso di Formazione Specifica in Medicina Generale. Perugia: Fondazione Angelo Celli, Istituto di Etnologia e Antropologia Culturale, Università degli Studi di Perugia, Ordine Provinciale dei Medici-Chirurghi e degli Odontoiatri, Sezione Provinciale di Perugia della Società Italiana di Medicina Generale (SIMG), (mimeo).

Shoor, S.; Lorig, K. R. (2002, April). Self-Care and the Doctor-Patient Relationship, Medical Care. 40(4) Supplement:II-40-II-44.

SIEMPOS I, I.; SPANOS, A.; ISSARIS, E. A.; RAFAILIDIS, P. I.; FALAGAS, M. E. (2008). Nonphysicians may reach correct diagnoses by using Google: a pilot study. Swiss Med Wkly, 138, 741-745.

Sinclair, F. In Need of TLC? A Doctor-Patient Relationship Fit for the Future, Scottish Council Foundation, 2007, http://www.scottishcouncilfoundation.org/page.php?id=25

Smith, R. (2001). Why are doctors so unhappy? BMJ, 322, 1073-1074. 
Sobes, J. J. M.; Santacreu, G. L.; Martínez, S. L.; Remón, C. A. (2009). Uso de internet por médicos de primaria y hospitales y percepción de como influye em su relación com los pacientes. Atención Primaria, 41(6), 308-314.

Sucupira, A. C. S. L. (1982). Relações Médico-Paciente nas Instituições de Saúde Brasileiras. Dissertação de Mestrado, São Paulo: Faculdade de Medicina, Universidade de São Paulo.

Taha, J.; Sharit, J.; Czaja, S. (2009). Use of and satisfaction with sources of health information among older internet users and nonusers. Gerontologist Review, 49, 66373.

Tang, H.; NG, J. H. (2006). Googling for a diagnosis: use of Google as a diagnostic aid: internet-based study. Br Med J, 333(7579), 1143-1145.

Usherwood, T. (1993). Subjective and behavioural evaluation of the teaching of patient interview skills. Medical Education, 27, 41-47.

Valle, A. B. et. al., (2010). Sistemas de informações gerenciais em organizações de saúde. Rio de Janeiro: FGV.

Walker, J. M.; Carayon, P. (2009, March/April). From tasks to processes: the case for changing health information technology to improve health care. Health Affairs 28(2), 467-477.

Watzlawick, P.; Helmick, J. B.; Jackson, D. D. (1972). Une Logique de la Communication. Paris: Éditions du Seuil.

WHO (World Health Organization) (2010). Doctor-Patient Interaction and Communication. Geneva: Division of Mental Health. WHO. 